\title{
Assessing Corrosion in Oil Refining and Petrochemical Processing
}

\author{
Randy C. John ${ }^{\mathrm{a} *}$, Arthur D. Pelton ${ }^{\mathrm{b}}$, Arthur L. Young ${ }^{\mathrm{c}}$, William T. Thompson ${ }^{\mathrm{d}}$, \\ Ian G. Wright ${ }^{\mathrm{e}}$, Theodore M. Besmann ${ }^{\mathrm{e}}$ \\ a Shell Global Solutions (US) Inc., P. O. Box 1380, Houston, Texas 77251-1380 USA \\ ${ }^{\mathrm{b}}$ CRCT, Ecole Polytechnique de Montréal, 447 Berwick, Montreal H3R 1Z8 Canada \\ ${ }^{\mathrm{c}}$ Humberside Solutions Ltd., Suite 1410, 270 Scarlett Road, Toronto, Ontario M6N 4X7 Canada \\ ${ }^{\mathrm{d}}$ Royal Military College of Canada, Kingston, Ontario, K7K 5LO Canada

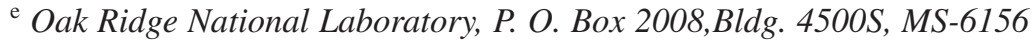 \\ Oak Ridge,Tennessee 37831-6156 USA
}

Received: September 2, 2002; Revised: September 4, 2002

\begin{abstract}
This paper summarizes the development of an information system used to manage corrosion of metals and alloys by high temperature gases found in many different oil refining, petrochemical, power generation, and chemical processes. The database currently represents about 7.9 million $\mathrm{h}$ of exposure time for about 5,500 tests with 89 commercial alloys for a temperature range of $200-$ $1,200{ }^{\circ} \mathrm{C}$. The system manages corrosion data from well-defined exposures and determines corrosion product stabilities. New models used in the analysis of thermochemical data for the $\mathrm{Fe}-\mathrm{Ni}$ - $\mathrm{Cr}$ Co-C-O-S-N-H system are being compiled. All known phases based upon combinations of the elements have been analyzed to allow complete assessments of corrosion product stabilities. Use of these data allows prediction of stable corrosion products and hence identification of the possible dominant corrosion mechanisms. The system has the potential to be used in corrosion research, alloy development, failure analysis, lifetime prediction, and process operations evaluations. The corrosion mechanisms emphasized are oxidation, sulfidation, sulfidation/oxidation, and carburization.
\end{abstract}

Keywords: oxidation, sulfidation, sulfidation/oxidation, carburization, ASSET, database, high temperature corrosion, total metal penetration, and engineering lifetime prediction

\section{Introduction}

This paper describes the development of a high-temperature corrosion information system. The capabilities include the ability to identify corrosion mechanisms in complex gases by using thermochemical models, and to predict alloy corrosion for wide ranges of exposure conditions found in many different processes.

The applications of this technology to management of corrosion in high-temperature gases includes prediction of sound metal losses for a wide range of conditions. Corrosion by hot gases is possible in processes such as: petroleum refining, gas processing, fired equipment, process heaters, burners, flares, furnaces, boilers, hydrocracking, coking, oil refining, hydrotreating, coal/coke/oil gasifying, petrochemical production, waste incineration, hydrogen plants, heat treatment, and electric heaters.

*e-mail: randy.john@shell.com

Presented at the International Symposium on High Temperature Corrosion in Energy Related Systems, Angra dos Reis - RJ, September 2002.
The ability to predict corrosion of alloys in high-temperature corrosive gases in many processes aids management of corrosion in many types of equipment. An important obstacle to predicting corrosion is the variety of the combinations of alloys and corrosive environments. Another obstacle is a lack of agreement on how to generate and then use high-temperature corrosion data to assess engineering lifetimes. The technology discussed in this article offers suggestions to deal with many alloys and corrosive conditions and provides a systematic method to predict corrosion in diverse conditions. Many aspects of equipment/process design, process operation, alloy selection, alloy design, and plant maintenance are influenced by the expected lifetimes of equipment in high-temperature, corrosive gases. These lifetimes are greatly affected by the 
conditions present in process equipment, because process equipment usually has maximum allowable temperatures, or other process conditions, which are limited by the corrosion rates expected for the equipment.

Most data for corrosion of alloys in high-temperature gases have been reported in terms of weight change/area for relatively short exposures and inadequately defined exposure conditions. Unfortunately, the weight change/area information does not directly relate to the thickness of corroded metal, which is often needed in assessing the strength of equipment components. Corrosion is best reported in penetration units, which indicate the sound metal loss, as discussed earlier ${ }^{1-3}$, and is shown in Fig. 1. Metal loss needs to be directly related to the loss of metal thickness used in equipment design and operation decision-making. Corrosion in high-temperature gases is affected by parameters of the corrosive environments such as temperature, alloy composition, time, and gas composition.

Benefits in improving the ability to manage corrosion data for alloys in high-temperature, corrosive gases will be far reaching in many industries. Examples are improvement in process safety, reduction in costs of maintenance of process operation, more cost-effective use of expensive alloys in equipment designs, reduction in the use of energy, moderation in the release of $\mathrm{CO}_{2}$ into the atmosphere and, of course, more confidence in use of alloys in extreme operating conditions in terms of allowable temperatures and gas compositions. All of these benefits are expected as a direct result of accurate predictions of corrosion for a wide range of commercially available metals and alloys exposed to complex, high-temperature gases.

Reductions in energy usage are now possible by more efficient use of fossil fuels through higher allowable equipment temperatures for some processes, while other processes may benefit from lower allowable temperatures as lower cost alloys can be used with more confidence, once their corrosion rates can be more accurately predicted. Enhanced productivity can be a direct result of improved prediction of alloy corrosion rates in high-temperature chemical process equipment and also for other processes. Equipment maintenance is also better scheduled and unplanned outages due to unexpected corrosion are reduced, by using this project technology.

The applications of the technology are in the following:

- equipment failure analysis to reduce maintenance costs and improve process safety;

- alloy evaluations to select cost effective alloys to design new alloys;

- equipment design/operation guidelines to optimize process economics;

- corrosion data management to archive and exploit data; and lifetime prediction and equipment inspection plans.
Eighty-nine commercial alloys are currently represented in the software, which contains 5,500 corrosion measurement records with a total exposure time of 7.9 million $\mathrm{h}$. The methodologies of corrosion mechanism determination and corrosion prediction are described in this paper. The general approach is the same for all mechanisms except that the form of the rate equation and the critical species differ. The system uses thermochemical calculations to predict the stable corrosion products and the equilibrium gas composition for many environments.

\section{Corrosion Mechanisms}

The stable corrosion products are used to determine the names of the corrosion mechanisms discussed in this paper. For example: oxides imply oxidation, sulfides imply sulfidation, sulfides plus oxides imply sulfidation/oxidation, and carbides imply carburization.

\section{Oxidation}

Oxidation often occurs upon exposure of metals to temperatures above $300^{\circ} \mathrm{C}$ in oxidizing gases. Examples of the types of process equipment where oxidation is a concern are fired equipment, combustors, process heaters, burners, furnace structural equipment/instrumentation, and flares. Common methods to confirm oxidation are either $\mathrm{X}$-ray analysis by diffraction of the surface scale or analysis of the gas composition.

The dependence of corrosion upon exposure time for alloys after sufficient time has passed is commonly assumed to be proportional to (time) $)^{0.5}$, which is known as parabolic time dependence. Several thousand h may be required to establish this time dependence. Oxidation measured after hundreds of $\mathrm{h}$ is unlikely to be useful in estimating long time oxidation rates. It is known that many alloys establish parabolic time dependence after times of $500-1,000 \mathrm{~h}$ in air at constant temperatures only of $870-1,090{ }^{\circ} \mathrm{C}^{2-3}$.

Most alloys tend to have increasing penetration rates with increasing temperature for all $\mathrm{O}_{2}$ concentrations. Some exceptions will be alloys with $1-4 \%$ Al concentrations, such as S67956 and N07214. See Table 1 for compositions and alloy names. These alloys need high temperatures to form $\mathrm{Al}_{2} \mathrm{O}_{3}$ as the dominant surface oxide, which grows more slowly than the $\mathrm{Cr}_{2} \mathrm{O}_{3}$, which dominates at the lower temperatures. Figure 2 summarizes oxidation after one year for some widely used alloys exposed to air for one year. The metal temperature is used in assessing the oxidation rate of metals and not the gas temperature.

The gas composition also influences the rate of oxidation, in terms of variables such as $\mathrm{P}_{2}$ (oxygen partial pressure). The influence of $\mathrm{P} \mathrm{O}_{2}$ on oxidation kinetics is specific to each alloy ${ }^{2-3}$. Figure 3 shows that some alloys show increasing corrosion with $\mathrm{P} \mathrm{O}_{2}$, while others slow as the 
Table 1. Compositions in wt $\%$ of Some Alloys in The Databases.

\begin{tabular}{|c|c|c|c|c|c|c|c|c|c|c|c|c|c|c|c|}
\hline Alloy Name & UNS & $\mathrm{Fe}$ & $\mathrm{Cr}$ & $\mathrm{Ni}$ & Co & Mo & $\mathrm{Al}$ & $\mathrm{Si}$ & $\mathrm{Ti}$ & W & $\mathrm{Mn}$ & $\mathrm{Cu}$ & $\operatorname{Re}^{*}$ & $\mathrm{C}$ & $\mathrm{Nb}$ \\
\hline $153 \mathrm{MA}$ & S30415 & 69.66 & 18.30 & 9.50 & 0.00 & 0.42 & 0.00 & 1.23 & 0.00 & 0.00 & 0.56 & 0.23 & 0.05 & 0.05 & 0.00 \\
\hline $253 \mathrm{MA}$ & S30815 & 65.60 & 20.90 & 11.00 & 0.00 & 0.00 & 0.00 & 1.77 & 0.00 & 0.00 & 0.64 & 0.00 & 0.00 & .09 & 0.00 \\
\hline $9 \mathrm{Cr} 1 \mathrm{Mo}$ & S50400 & 88.61 & 8.90 & 0.00 & 0.00 & 1.03 & 0.00 & 0.86 & 0.00 & 0.00 & 0.47 & 0.00 & 0.00 & 0.13 & 0.00 \\
\hline ACI HK40 & J94224 & 50.65 & 25.10 & 21.20 & 0.00 & 0.00 & 0.44 & 1.35 & 0.37 & 0.00 & 0.60 & 0.00 & 0.00 & 0.29 & 0.00 \\
\hline ACI HP-Nb & 195705 & 31.90 & 24.65 & 38.75 & 0.00 & 1.46 & 0.00 & 1.65 & 0.43 & 0.00 & 1.01 & 0.00 & 0.00 & 0.15 & 1.00 \\
\hline AISI 1020 & G10200 & 99.42 & 0.00 & 0.00 & 0.00 & 0.00 & 0.00 & 0.04 & 0.00 & 0.00 & 0.38 & 0.00 & 0.00 & 0.16 & 0.00 \\
\hline AISI 304 & S30400 & 71.07 & 18.28 & 8.13 & 0.14 & 0.17 & 0.00 & 0.49 & 0.00 & 0.00 & 1.48 & 0.19 & 0.00 & 0.05 & 0.00 \\
\hline AISI 310 & S31000 & 52.41 & 24.87 & 19.72 & 0.05 & 0.16 & 0.00 & 0.68 & 0.00 & 0.00 & 1.94 & 0.11 & 0.00 & 0.06 & 0.00 \\
\hline AISI 316 & S31600 & 68.75 & 17.00 & 12.00 & 0.00 & 2.25 & 0.00 & 0.00 & 0.00 & 0.00 & 0.00 & 0.00 & 0.00 & 0.00 & 0.00 \\
\hline AISI 321 & S32100 & 69.94 & 17.22 & 9.85 & 0.21 & 0.14 & 0.00 & 0.46 & 0.43 & 0.00 & 1.61 & 0.10 & 0.00 & 0.04 & 0.00 \\
\hline AISI 347 & S34700 & 68.14 & 17.75 & 10.75 & 0.00 & 0.00 & 0.00 & 0.55 & 0.00 & 0.00 & 1.80 & 0.00 & 0.00 & 0.05 & 0.96 \\
\hline AISI 410 & S41000 & 86.50 & 12.30 & 0.50 & 0.00 & 0.10 & 0.00 & 0.60 & 0.00 & 0.00 & 0.00 & 0.00 & 0.00 & 0.00 & 0.00 \\
\hline AISI 446 & S44600 & 74.12 & 24.36 & 0.36 & 0.02 & 0.20 & 0.00 & 0.33 & 0.00 & 0.00 & 0.45 & 0.10 & 0.00 & 0.06 & 0.00 \\
\hline Alloy 188 & R30188 & 1.32 & 21.98 & 22.82 & 38.00 & 0.00 & 0.00 & 0.37 & 0.00 & 14.55 & 0.82 & 0.00 & 0.04 & 0.10 & 0.00 \\
\hline Alloy 214 & N07214 & 2.49 & 16.04 & 76.09 & 0.14 & 0.10 & 4.71 & 0.10 & 0.00 & 0.10 & 0.20 & 0.00 & 0.00 & 0.03 & 0.00 \\
\hline Alloy 230 & N06230 & 1.30 & 21.90 & 59.70 & 0.28 & 1.20 & 0.38 & 0.42 & 0.02 & 14.20 & 0.49 & 0.01 & 0.00 & 0.10 & 0.00 \\
\hline Alloy 556 & R30556 & 32.50 & 21.27 & 21.31 & 18.09 & 2.88 & 0.17 & 0.33 & 0.00 & 2.38 & 0.96 & 0.00 & 0.00 & 0.11 & 0.00 \\
\hline Alloy 600 & N06600 & 7.66 & 15.40 & 75.81 & 0.00 & 0.00 & 0.32 & 0.16 & 0.00 & 0.00 & 0.29 & 0.32 & 0.00 & 0.04 & 0.00 \\
\hline \multicolumn{16}{|l|}{ Alloy } \\
\hline $601 \mathrm{GC}$ & N06601 & 13.53 & 23.48 & 60.00 & 0.06 & 0.16 & 1.26 & 0.50 & 0.27 & 0.00 & 0.31 & 0.38 & 0.00 & 0.05 & 0.00 \\
\hline Alloy 617 & N06617 & 0.76 & 22.63 & 53.20 & 12.33 & 9.38 & 1.15 & 0.15 & 0.27 & 0.00 & 0.02 & 0.05 & 0.00 & 0.06 & 0.00 \\
\hline Alloy 625 & N06625 & 2.66 & 21.74 & 62.79 & 0.00 & 8.46 & 0.10 & 0.41 & 0.19 & 0.00 & 0.10 & 0.00 & 0.00 & 0.03 & 3.52 \\
\hline Alloy $800 \mathrm{H}$ & N08810 & 44.22 & 21.22 & 31.71 & 0.00 & 0.00 & 0.33 & 0.60 & 0.41 & 0.00 & 0.92 & 0.51 & 0.00 & 0.08 & 0.00 \\
\hline Alloy 803 & & 35.94 & 26.19 & 35.04 & 0.21 & 0.01 & 0.58 & 0.63 & 0.33 & 0.00 & 0.98 & 0.00 & 0.00 & 0.09 & 0.00 \\
\hline Alloy DS & & 44.31 & 16.60 & 34.90 & 0.00 & 0.29 & 0.00 & 2.52 & 0.00 & 0.00 & 1.14 & 0.17 & 0.00 & 0.07 & 0.00 \\
\hline Cooper & C11000 & 0.00 & 0.00 & 0.00 & 0.00 & 0.00 & 0.00 & 0.00 & 0.00 & 0.00 & 0.00 & 100.00 & 0.00 & 0.00 & 0.00 \\
\hline HR-120 & N08120 & 34.53 & 25.12 & 37.44 & 0.11 & 0.37 & 0.11 & 0.57 & 0.02 & 0.00 & 0.73 & 0.18 & 0.00 & 0.06 & 0.66 \\
\hline HR-160 & N12160 & 8.00 & 28.00 & 34.30 & 27.00 & 0.00 & 0.00 & 2.70 & 0.00 & 0.00 & 0.00 & 0.00 & 0.00 & 0.00 & 0.00 \\
\hline Incoloy & S67956 & 75.22 & 19.40 & 0.28 & 0.05 & 0.00 & 4.50 & 0.11 & 0.33 & 0.00 & 0.09 & 0.00 & 0.00 & 0.02 & 0.00 \\
\hline \multicolumn{16}{|l|}{ MA956 } \\
\hline Nickel & N02270 & 0.00 & 0.00 & 99.99 & 0.00 & 0.00 & 0.00 & 0.00 & 0.00 & 0.00 & 0.00 & 0.00 & 0.00 & 0.01 & 0.00 \\
\hline $602 \mathrm{CA}$ & N06025 & 9.45 & 25.35 & 62.63 & 0.00 & 0.00 & 2.09 & 0.06 & 0.14 & 0.00 & 0.09 & 0.01 & 0.00 & 0.18 & 0.00 \\
\hline
\end{tabular}

* Re: Rare earth elements.

$\mathrm{P} \mathrm{O}_{2}$ increases. Alloys such as S67956, N08120, and N07214 exhibit slower oxidation rates as the $\mathrm{O}_{2}$ concentration increases. These alloys form surface oxides rich in $\mathrm{Cr}$ or $\mathrm{Al}$, whose oxides are stabilized by increasing levels of $\mathrm{PO}_{2}$. Some alloys, which generally exhibit increased oxidation rates as the $\mathrm{O}_{2}$ concentration increases, are $\mathrm{S} 30400$, S41000, S50400, Incoloy DS, N06617, S44600, and S30815. These alloys form rapidly growing oxide scales and increasing levels of $\mathrm{O}_{2}$ concentration increase the growth rates of the corroding alloy components, thereby increasing the corrosion rate.

Many commercial heat resistant alloys show about $80-95 \%$ of the total penetration as subsurface oxidation ${ }^{2-3}$. Some alloys differ in how much of the total penetration occurs by subsurface oxidation as time passes, until longterm behavior is established, even though the corrosion product morphologies may remain fairly constant.

\section{Sulfidation}

Sulfidation can occur upon exposure of metals to temperatures above approximately $200{ }^{\circ} \mathrm{C}$ in gases containing
$\mathrm{H}_{2} \mathrm{~S}$ at partial pressures greater than $1 \times 10^{-6}$ atma. Examples of the types of process equipment where sulfidation is a concern are hydrotreater charge furnaces, crude distilling columns, vacuum flashers, petroleum coking units, and sulfur removal plants (gas sweetening plants). The presence of sulfides confirms sulfidation. Sulfidation occurs upon exposure of metals to gases containing $\mathrm{CO}-\mathrm{CO}_{2}-\mathrm{COS}-\mathrm{H}_{2}-\mathrm{H}_{2} \mathrm{O}-\mathrm{H}_{2} \mathrm{~S}$. Common methods to confirm sulfidation are either X-ray analysis by diffraction of the surface scale or analysis of the gas composition. Variables that influence the sulfidation rate are the exposure time, and partial pressures of $\mathrm{H}_{2}$ and $\mathrm{H}_{2} \mathrm{~S}$, and temperature.

The time dependence of sulfidation is controversial ${ }^{4-12}$ with reports of a parabolic time dependence, linear time dependence (metal loss proportional to time), power law dependence (metal loss proportional to timex), and combinations of these dependencies. An undisturbed sulfide scale and exposure time in excess of 2,000 h, probably yield parabolic time dependence. Some studies, however, report linear time dependence after several thousand $\mathrm{h}^{4,5}$.

The first step in assessing the rate of sulfidation is to 


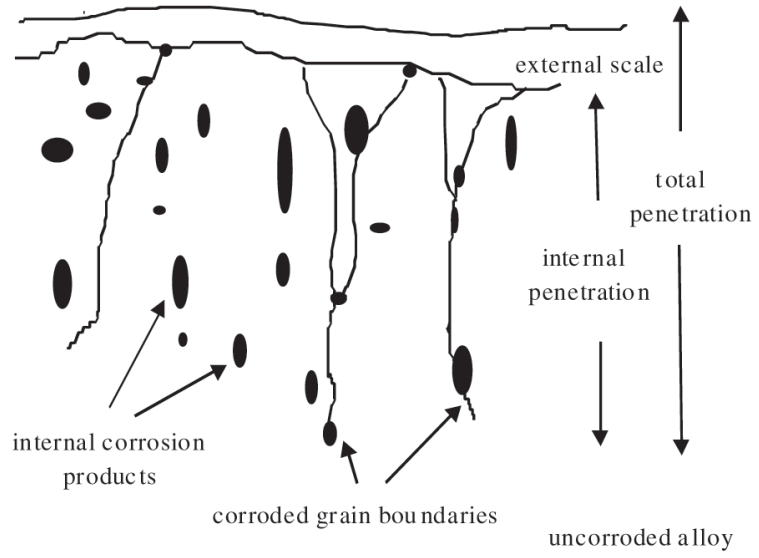

Figure 1. Schematic View of Total Penetration Measurement for a Typical Corrosion Product Morphology

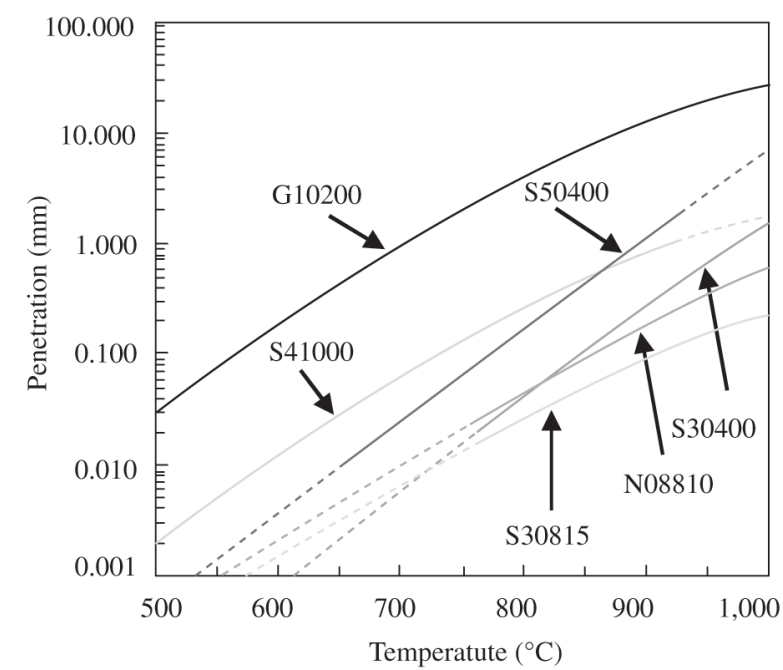

Figure 2. Effect of Temperature Upon Metal Penetration of Some Common Alloys by Oxidation After Exposure for One Year to Air ( $\mathrm{P} \mathrm{O}_{2}$ of 0.21 atma).

evaluate the potential for sulfide corrosion products to form. Confirmation of sulfides on existing equipment or a thermochemical evaluation of the corrosive gas to produce sulfides may be done by analyses of corrosion products, use of well-known compilations ${ }^{6-12}$, or thermochemical calculations ${ }^{13}$. Once sulfidation is expected, one can predict sulfidation rates by using either the traditional sulfidation curves for corrosion in $\mathrm{H}_{2} \mathrm{~S}-\mathrm{H}_{2}$ gases or the curves of the type shown in this presentation, including the effects of temperature, gas composition, and alloy composition. One important concept often assumed is that extensive sulfidation corrosion cannot occur below the line shown to

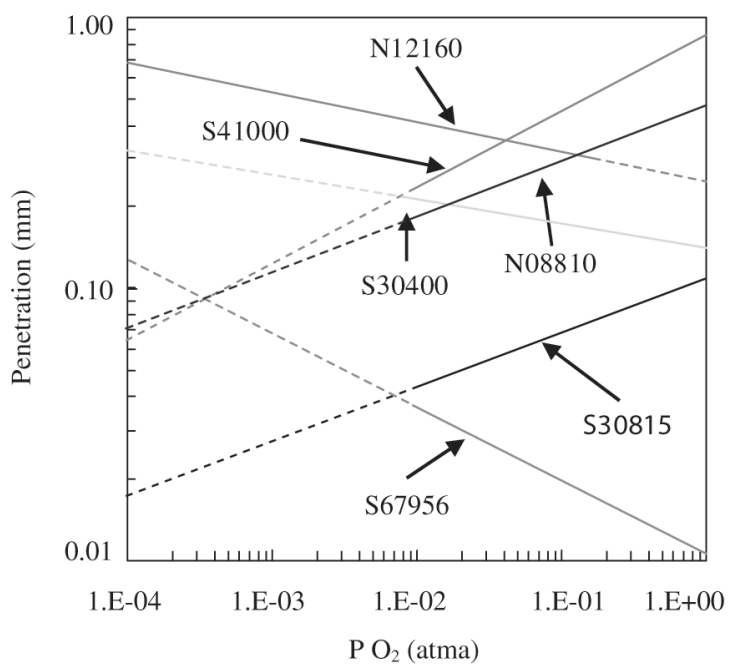

Figure 3. Effect of $\mathrm{P} \mathrm{O}_{2}$ Upon Oxidation Corrosion of a Range of Alloys at $900{ }^{\circ} \mathrm{C}$ After One Year.

progress from the lower left to the upper right, as illustrated in Fig. 4 for steels. This line represents the limiting conditions for formation of $\mathrm{FeS}$, which is the primary corrosion product of carbon/low alloy steels $(<5 \% \mathrm{Cr})$ during sulfidation in contact with $\mathrm{H}_{2}-\mathrm{H}_{2} \mathrm{~S}$ gases. $\mathrm{H}_{2} \mathrm{~S}$ concentrations above the line favor formation of FeS, which is a requirement for sulfidation of iron and low alloy steels. It should be noted that it is incorrect to indicate that alloys with significant concentrations of $\mathrm{Cr}$ cannot corrode at conditions representing lower $\mathrm{H}_{2} \mathrm{~S}$ concentrations and higher temperatures indicated by this line. Alloys with $\mathrm{Cr}$ can form $\mathrm{CrS}$, which forms at lower $\mathrm{H}_{2} \mathrm{~S}$ concentrations and higher temperatures than needed to form $\mathrm{FeS}$ on low alloy steels. Figure 4 shows the limits of $\mathrm{H}_{2} \mathrm{~S}$ concentration and temperature corresponding to corrosion products of Cr. Alloys with greater than $5 \% \mathrm{Cr}$ can corrode in conditions where low alloy steels cannot corrode. The corrosion rates may be low (such as $0.025-0.25 \mathrm{~mm}$ per year) but significant for conditions where steels have been traditionally thought to be immune to sulfidation. The effects of temperature and $\mathrm{H}_{2} \mathrm{~S}$ concentration upon sulfidation of steels often used in oil refining services are shown in Figs. 5-6, which represent metal losses expected after one year of exposure. Figure 5 shows sulfidation predictions of several simple metals. Figure 6 shows sulfidation predications of a range of alloys for a range of $\mathrm{H}_{2} \mathrm{~S}$ values. Increasing the temperature and $\mathrm{H}_{2} \mathrm{~S}$ concentration increase the sulfidation rate. It is typical that a temperature increase of $50{ }^{\circ} \mathrm{C}$ will double the sulfidation rate, while increasing the $\mathrm{H}_{2} \mathrm{~S}$ concentration by a factor of 10 may be needed to double the sulfidation rate. Therefore, changes of $\mathrm{H}_{2} \mathrm{~S}$ concentration are generally less significant, in terms of influencing corrosion, than temperature varia- 


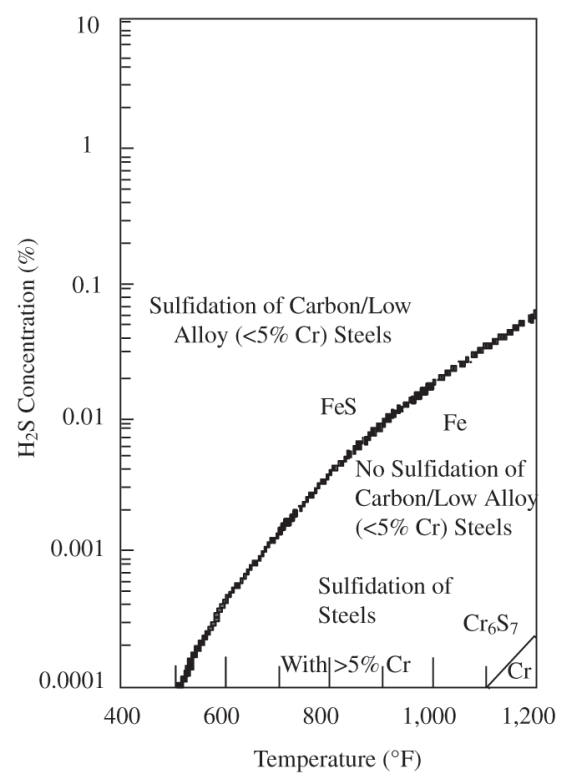

Figure 4. Conditions for Possible Sulfidation, Based Upon $\mathrm{H}_{2} \mathrm{~S}$ Concentrations in $\mathrm{H}_{2}-\mathrm{H}_{2} \mathrm{~S}$ Gases and Temperatures Above the $\mathrm{FeS} / \mathrm{Fe}$ Line for Carbon/Low Alloy (5\% Cr) Steels and Above the $\mathrm{Cr}_{6} \mathrm{~S}_{7} / \mathrm{Cr}$ Line for Alloys with $>5 \% \mathrm{Cr} .400-1,200{ }^{\circ} \mathrm{F}=204-648^{\circ} \mathrm{C}$.

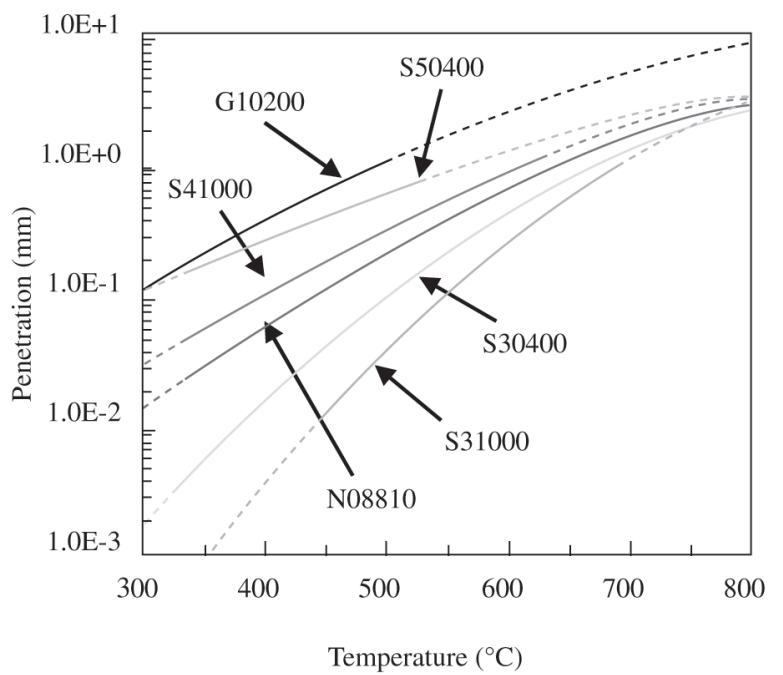

Figure 5. Effect of Temperature Upon Sulfidation Corrosion of Some Alloy Commonly Used in Sulfidizing Conditions After One Year 0.05 atma $\mathrm{H} 2 \mathrm{~S}$ and 0.5 atma $\mathrm{H}_{2} \mathrm{~S}$ and 0.5 atma $\mathrm{H}_{2}$.

tions. Increasing the $\mathrm{Cr}$ content of the alloy greatly slows the sulfidation, as seen in progression from $9 \% \mathrm{Cr}$ (S50400), $12 \% \mathrm{Cr}$ (S41000), 18\% Cr (S30400), 20\% Cr (N08810), and $25 \% \mathrm{Cr}$ (N08825 and N06625). The ranges of $\mathrm{H}_{2} \mathrm{~S}$ concen-

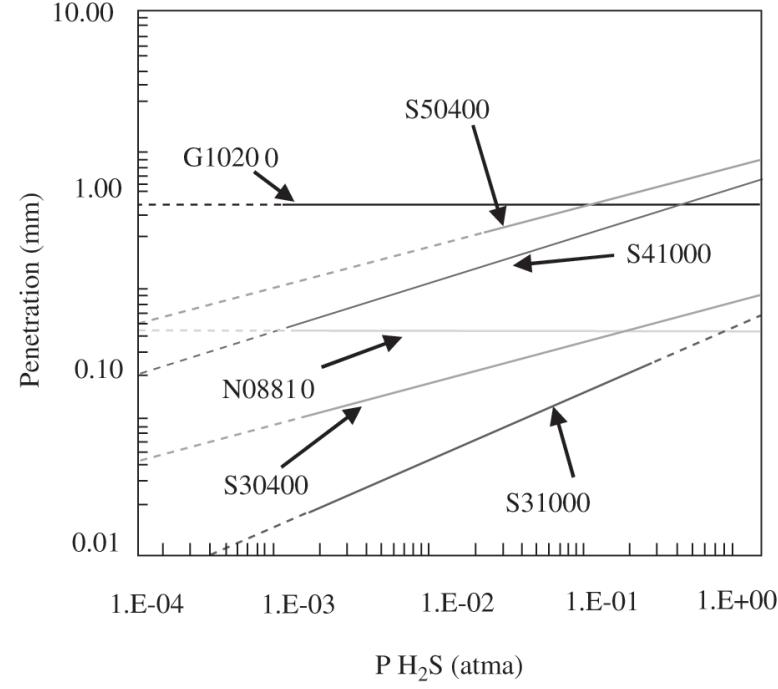

Figure 6. Effect of $\mathrm{H}_{2} \mathrm{~S}$ Partial Pressure Upon the Sulfidation Corrosion After One Year in $\mathrm{H}_{2} \mathrm{~S}$ Gases at a total Pressure of One Atma at 500 .

tration represented in these figures span the low $\mathrm{H}_{2} \mathrm{~S}$ of catalytic reformers to the high $\mathrm{H}_{2} \mathrm{~S}$ levels expected in modern hydrotreaters. These curves are in good agreement with the traditional data ${ }^{8-13}$.

\section{Sulfidation/oxidation}

Sulfidation/oxidation occurs upon exposure of alloys containing elements such as $\mathrm{Cr}$ and $\mathrm{Al}$ to hot gases containing various combinations of CO-CO $-\mathrm{COS}-\mathrm{H}_{2}-\mathrm{H}_{2} \mathrm{O}-\mathrm{H}_{2} \mathrm{~S}$ gases. Examples of the types of process equipment where sulfidation/oxidation is a concern are hydrocrackers, hydrotreaters, coal/coke/oil gasifiers, crude distilling columns, vacuum flashers, sulfur removal plants and Flexicokers. Sulfidation/oxidation occurs when corrosion products are mixtures of sulfides and oxides. Elements such as $\mathrm{Cr}, \mathrm{Al}$, and $\mathrm{Si}$ may be present in oxides, while $\mathrm{Fe}, \mathrm{Ni}$, and $\mathrm{Co}$ may be present in sulfides. Pure metals such as $\mathrm{Fe}$, low alloy steels, or $\mathrm{Ni}$ form either sulfides or oxides and rarely undergo sulfidation/oxidation. Common methods to confirm sulfidation/oxidation are either X-ray analysis by diffraction of the surface scale or analysis of the gas composition.

The important variables for sulfidation/oxidation of each alloy are the alloy composition, $\mathrm{P}_{2}$ and $\mathrm{P}_{2}$, metal temperature, and time. The $\mathrm{P}_{2}$ can be calculated by using the partial pressure ratios of $\mathrm{H}_{2} \mathrm{O} / \mathrm{H}_{2}$ or $\mathrm{CO}_{2} / \mathrm{CO}$ and metal temperature ${ }^{13}$. The $\mathrm{P}_{2}$ can be calculated by using the partial pressure ratios of $\mathrm{H}_{2} \mathrm{~S} / \mathrm{H}_{2}$ or $\mathrm{CO} / \mathrm{COS}$ and metal temperature $^{13}$. 
The presence of oxidizing gases such as $\mathrm{H}_{2} \mathrm{O}$ or $\mathrm{CO}_{2}$ slows the sulfidation rate below that expected if only $\mathrm{H}_{2} \mathrm{~S}$ $\mathrm{H}_{2}$ were present. This is important because gases, which are thought to contain only $\mathrm{H}_{2} \mathrm{~S}-\mathrm{H}_{2}$ often also contain some $\mathrm{H}_{2} \mathrm{O}$, because of exposure to liquid water. A gas exposed to water at room temperature (such as a water wash in a process) may contain up to $2 \%$ water in the gas, if saturated with water at room temperature. Sulfidation rates predicted using the $\mathrm{H}_{2} \mathrm{~S}-\mathrm{H}_{2}$ concentrations might overestimate the rate, if $\mathrm{H}_{2} \mathrm{O}$ is present. This slowed corrosion rate can be thought of as a transition between rapid corrosion of sulfidation and slow corrosion of oxidation. This is illustrated in Fig. 7 for $\mathrm{S} 30400, \mathrm{~S} 3100$ and $\mathrm{N} 08810$ at $700{ }^{\circ} \mathrm{C}$ in a gas $\mathrm{H}_{2} \mathrm{~S}-\mathrm{H}_{2}-$ $\mathrm{H}_{2} \mathrm{O}$, based upon the analysis methods discussed earlier ${ }^{13}$ and reviewed in this article. The right-hand $\mathrm{PO}_{2}$ corresponds to air, while the left-hand $\mathrm{PO}_{2}$ corresponds to $\mathrm{O}_{2}$-depleted conditions (sulfidation). The minimum rate is rate of oxidation in $\mathrm{O}_{2}$-containing gases and the maximum rate is rate of sulfidation in $\mathrm{H}_{2} \mathrm{~S}-\mathrm{H}_{2}$ gases.

\section{Carburization}

Carburization forms carbide corrosion products and occurs upon exposure of metals to temperatures above approximately $700{ }^{\circ} \mathrm{C}$ in gases containing $\mathrm{CH}_{4}, \mathrm{CO}$, hydrocarbons, and solid carbon. Examples of the types of process equipment where carburization is a concern are ethylene furnace tubes (steam cracking of hydrocarbons) and steam methane reforming tubes for hydrogen production. The first step in determining the potential for carburization is to confirm that carbides are present. Common methods to confirm carburization are either X-ray analysis by diffraction of the surface scale or analysis of the gas composition. Variables, which influence the carburization rate are the temperature, exposure time, partial pressures of $\mathrm{H}_{2}, \mathrm{CH}_{4}, \mathrm{H}_{2} \mathrm{~S}$, and alloy composition. Suitable data from previous work ${ }^{18-}$ ${ }^{24}$ have been compiled and added into the databases. Alloys tend to have more penetration with increasing temperature for all gas conditions. Figure 8 summarizes carburization after one year for some alloys exposed to carbon and $2 \times 10^{-}$ ${ }^{4}$ atma $\mathrm{H}_{2} \mathrm{~S}$.

The time dependence of carburization is often parabolic. One thousand $\mathrm{h}$ may be required to establish the time dependence expected for long-term service, suggesting that carburization rates measured after periods of only hundreds of $\mathrm{h}$ (as is often the case for available data) may not be useful in estimating carburization corrosion rates for longterm service.

Increasing the concentration of $\mathrm{H}_{2} \mathrm{~S}$ tends to slow the carburization rate of alloys. Figure 9 shows the effect for several alloys widely used in petrochemical equipment. The $\mathrm{H}_{2} \mathrm{~S}$ slows decomposition of the $\mathrm{CH}_{4}$, which adsorbs onto the metal surface, thus slowing the rate of carburiza-

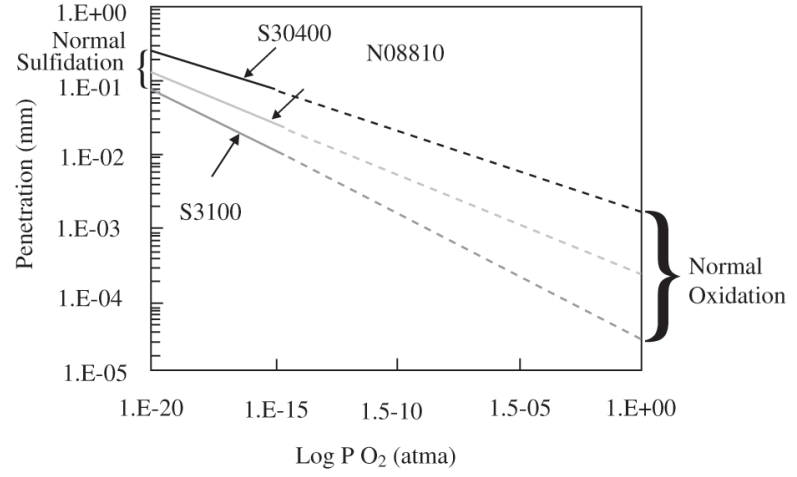

Figure 7. Effect of $\mathrm{H}_{2} \mathrm{O}$ or $\mathrm{CO}_{2}$, as Indicated in the $\mathrm{PO}_{2}$ Upon the Extent of Sulfidation/Oxidation of Several Alloys at $700{ }^{\circ} \mathrm{C}$ in $\mathrm{H}_{2}-$ $\mathrm{H}_{2} \mathrm{~S}-\mathrm{H}_{2} \mathrm{O}$ Gases, after one year.

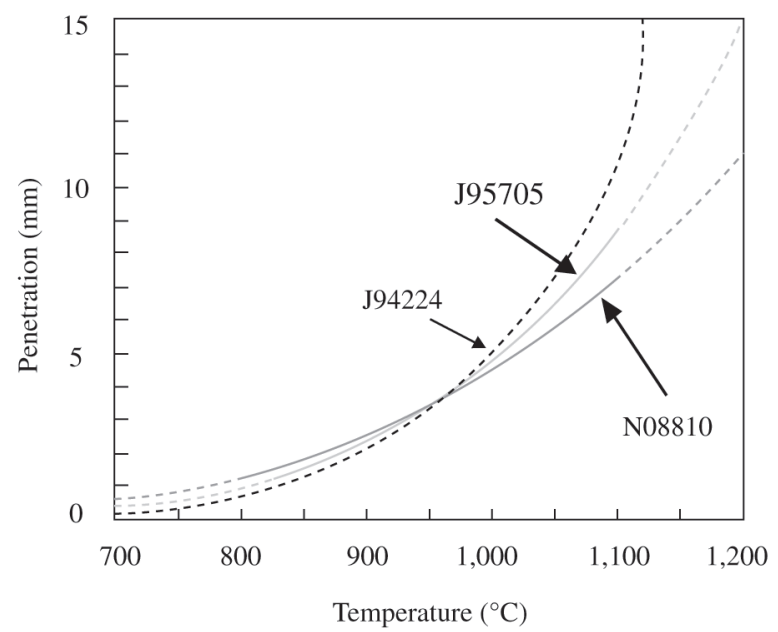

Figure 8. Effect of Temperature Upon Carburization of Several Alloys Exposed to Solid Carbon and $2 \times 10^{-4}$ atma $\mathrm{H}_{2} \mathrm{~S}$ After One Year.

tion. Increasing concentrations will slow carburization, until the concentrations are high enough to sulfide the alloy. The conditions for the initiation of sulfidation depend upon the alloy and gas compositions. Approximately this means a concentration of $300 \mathrm{ppm}$ (vol.) of $\mathrm{H}_{2} \mathrm{~S}$ for ethylene furnace conditions containing hydrocarbons and steam at $980-1,090{ }^{\circ} \mathrm{C}$.

\section{Technology Development}

Now that we have reviewed some concepts on corrosion data interpretation, we'll now discuss the development of a technology to provide alloy corrosion predictions. The project started in early 2000 and is producing 


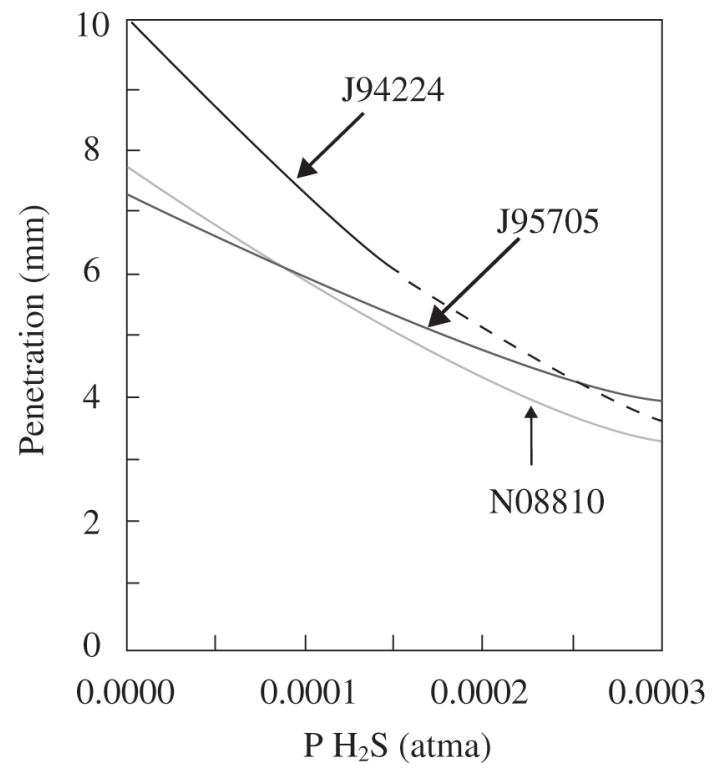

Figure 9. Effect of $\mathrm{PH}_{2} \mathrm{~S}$ Upon Carburization of Several Alloys Exposed to Carbon Activity of 1.0 in $\mathrm{H}_{2} \mathrm{~S}$ - Containing Gases at $1000{ }^{\circ} \mathrm{C}$, after one year.

software that includes a database and thermochemical calculation programs that use corrosion data from well-controlled conditions to predict corrosion for alloys over a range of high-temperature corrosive environments. The project is improving corrosion predictions for alloys in gases at temperatures of $250-1,150{ }^{\circ} \mathrm{C}$. The project goals involve four main tasks, as described.

\section{Software Development}

Humberside Solutions provides the software development by incorporating additional corrosion data, distributing software, and instructing participants in the operation of the software.

\section{Thermochemical Modeling}

The Center for Research in Computational Thermochemistry of Ecole Polytechnic de Montreal, evaluates available thermochemical data to produce consistent data sets. This will improve the accuracy of predictions of corrosion mechanism, by determining the most stable corrosion products formed by alloys in contact with the gas. The data include the system of $\mathrm{Fe}-\mathrm{Cr}-\mathrm{Ni}-\mathrm{Co}-\mathrm{C}-\mathrm{S}-\mathrm{O}-\mathrm{N}-\mathrm{H}$, over the temperature range of $250-1,200{ }^{\circ} \mathrm{C}$, with the data covering conditions applicable to many industrial processes.

The new thermochemical database for the Fe-Co-Ni-Cr$\mathrm{C}-\mathrm{N}-\mathrm{O}$ system is now complete. All thermodynamic and phase diagram data have been critically evaluated and modeled for all metallic carbide and nitride compounds and solutions. Maximum carbon, cobalt, chromium and nickel concentrations apply to commercial alloys. The new oxide models take into account the latest experimental data, magnetic contributions to thermodynamic properties, cation distributions and vacancies in spinel phases. The new database includes a complete re-evaluation and optimization of non-stoichiometric wustite and magnetite. Work on the updating of the sulfide phases in the Fe-Cr-Ni-Co-S system is in progress. The routine that calculates equilibria of alloys, corrosion products, and gases is "ChemApp", which consists of the latest Gibbs' energy minimization routine of FACT $^{25}$ as well as all FACT solution model subroutines.

\section{Corrosion Testing Plan for the Project}

Corrosion is being determined under well-defined conditions, according to guidelines, which have been rigorously established, and the data stored in defined formats.The testing plan is shown in Table 2 .

\section{Oxidation}

The oxidation testing generates data in three environments: air, $\mathrm{N}_{2}+1 \% \mathrm{O}_{2}$, and $\mathrm{O}_{2}$, at the temperatures of $300-1,180{ }^{\circ} \mathrm{C}$, Oxygen partial pressure $\left(\mathrm{P}_{\mathrm{O} 2}\right)$ range of 0.01-1.0 atma for oxidizing conditions, and exposure times of up to $24,000 \mathrm{~h}$. Examples of the alloys tested are:

Copper, S30415, S30815, S34700, Incoloy DS, Incoloy 803, N06625, N06600, N12160, Nickel, S30400, S31000, S31600, N08810, and S67956.

\section{Sulfidation}

The sulfidation testing generates data in environments containing $\mathrm{H}_{2}$ and $\mathrm{H}_{2} \mathrm{~S}$. The $\mathrm{H}_{2} \mathrm{~S}$ partial pressures range from

Table 2. Test Plan for conditions being used to generate corrosion data.

\begin{tabular}{l|c|c|c}
\hline & Year One & Year Two & Year Three \\
\hline Mixed Gases & Sulfidation & Sulfidation/Oxidation & Carburization \\
\hline Oxidation & Low $\mathrm{O}_{2}(0.01 \mathrm{atma})$ & \multicolumn{2}{|c}{ High O$_{2}(1 \mathrm{atma})$} \\
\hline Oxidation & Air & Air & Air \\
\hline
\end{tabular}


0.001-0.20 atma and the $\mathrm{P}_{\mathrm{H} 2}$ ranges from 0.05 to 1 atma, at temperatures of $300-800{ }^{\circ} \mathrm{C}$.

Examples of the alloys tested are:

S30415, S30815, S30400, S31000, S34700, S44600, N06600, N08810, N12160, N08120, Incoloy DS, S41000, S31600, and S67956

\section{Sulfidation/Oxidation}

The sulfidation/oxidation tests were done with gas mixtures of CO- $\mathrm{CO}_{2}-\mathrm{COS}$. The $\mathrm{P}_{\mathrm{S} 2}$ ranges from $1 \times 10^{-5}$ to $1 \times 10^{-}$ ${ }^{3}$ atma and the $\mathrm{P}_{\mathrm{O} 2}$ ranges from $1 \times 0^{-24}$ to $1 \times 10^{-14}$ atma at temperatures of $300-900{ }^{\circ} \mathrm{C}$. Exposure times were up to $6,000 \mathrm{~h}$. Examples of the alloys tested are:

S30400, S31400, S31600, S31700, S34700, S41000, N06600, N06601, N06025, N06617, 803, DS, N12160, N08120, S30415, S30815, S67956, and N0214

\section{Carburization}

The carburization tests are in environments containing mixtures of $\mathrm{CH}_{4}-\mathrm{H}_{2}-\mathrm{H}_{2} \mathrm{~S}$. The carbon activities will range from 0.5-1.0 and the $\mathrm{P}_{\mathrm{H}_{2} \mathrm{~S}}$ ranges up to $3 \times 10^{-4}$ atma. Exposure times are up to $6,000 \mathrm{~h}$ and test temperatures are 800-1, $150{ }^{\circ} \mathrm{C}$. Examples of the alloys being tested are:

S30400, S31000, S41000, N06600, 602CA, Incoloy 803, Incoloy DS, N12160, N08120, S30415, S30815, S67956, N07718, N008810, S50400, N06025, ACI HK40, and ACI HP NB.

\section{Generalized Procedure for Corrosion Predictions}

The methodologies discussed in this paper have been built into software ${ }^{26-32}$. The software uses the alloy composition and the corrosive environment information to calculate the stable corrosion products and the equilibrium gas composition, for a given combination of alloy and exposure conditions. This is illustrated in Fig. 10. The gas composition and stable corrosion products are calculated after providing information on the alloy gas composition and the temperature. The stable corrosion products are calculated assuming a small amount of metal and a large amount of gas, which is intended to approximate the corrosion product/gas interface. The computations use the ChemApp program from $\mathrm{F}^{*} \mathrm{~A} * \mathrm{C} * \mathrm{~T}^{25}$. The thermodynamic solution behaviors of the solid and liquid alloys and the solid and liquid corrosion products are considered. Thermochemical characteristics such as the $\mathrm{P}_{\mathrm{O}_{2}}, \mathrm{P}_{\mathrm{S}_{2}}$, and carbon activity of the environment, which help determine corrosion product stabilities are also determined by the software. The software assists identification of the likely corrosion mechanism, by knowing the stable corrosion products at the cor-

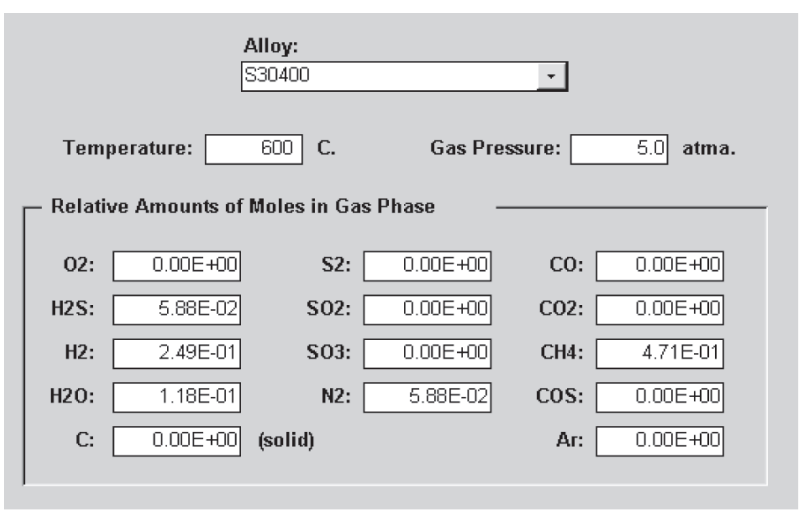

Input Gas and Temperature Information

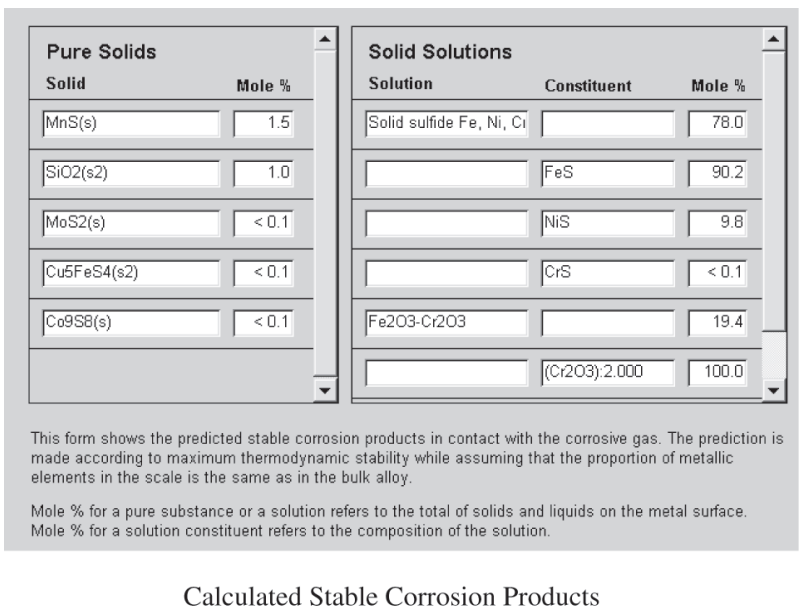

\begin{tabular}{|c|c|c|}
\hline Species & $\begin{array}{l}\text { Partial Press. } \\
\text { (atma) }\end{array}$ & $\begin{array}{l}\text { Relative no. } \\
\text { of moles }\end{array}$ \\
\hline $\mathrm{H} 2$ & $2.02 \mathrm{E}+00$ & $4.04 \mathrm{E}-01$ \\
\hline $\mathrm{CH} 4$ & $1.88 E+00$ & $3.77 \mathrm{E}-01$ \\
\hline $\mathrm{H} 2 \mathrm{O}$ & $4.49 E-01$ & $8.99 \mathrm{E}-02$ \\
\hline $\mathrm{H} 2 \mathrm{~S}$ & $2.80 \mathrm{E}-01$ & $5.60 \mathrm{E}-02$ \\
\hline $\mathbb{N 2}$ & $2.79 \mathrm{E}-01$ & $5.59 E-02$ \\
\hline $\mathrm{CO}$ & $5.15 \mathrm{E}-02$ & $1.03 \mathrm{E}-02$ \\
\hline
\end{tabular}

Calculated Equilibrium Gas Composition

Figure 10. Example Screens for Alloy S30400 Exposed to a Complex Gas Analyzed to Predict the Stable.

rosion product/corrosive gas interface, the alloy in question, and the gas thermochemistry. Different alloys in the same exposure conditions may exhibit different stable corrosion products and different corrosion mechanisms.

In the absence of experimental data for the specific conditions of interest, predictions made by using the approach 

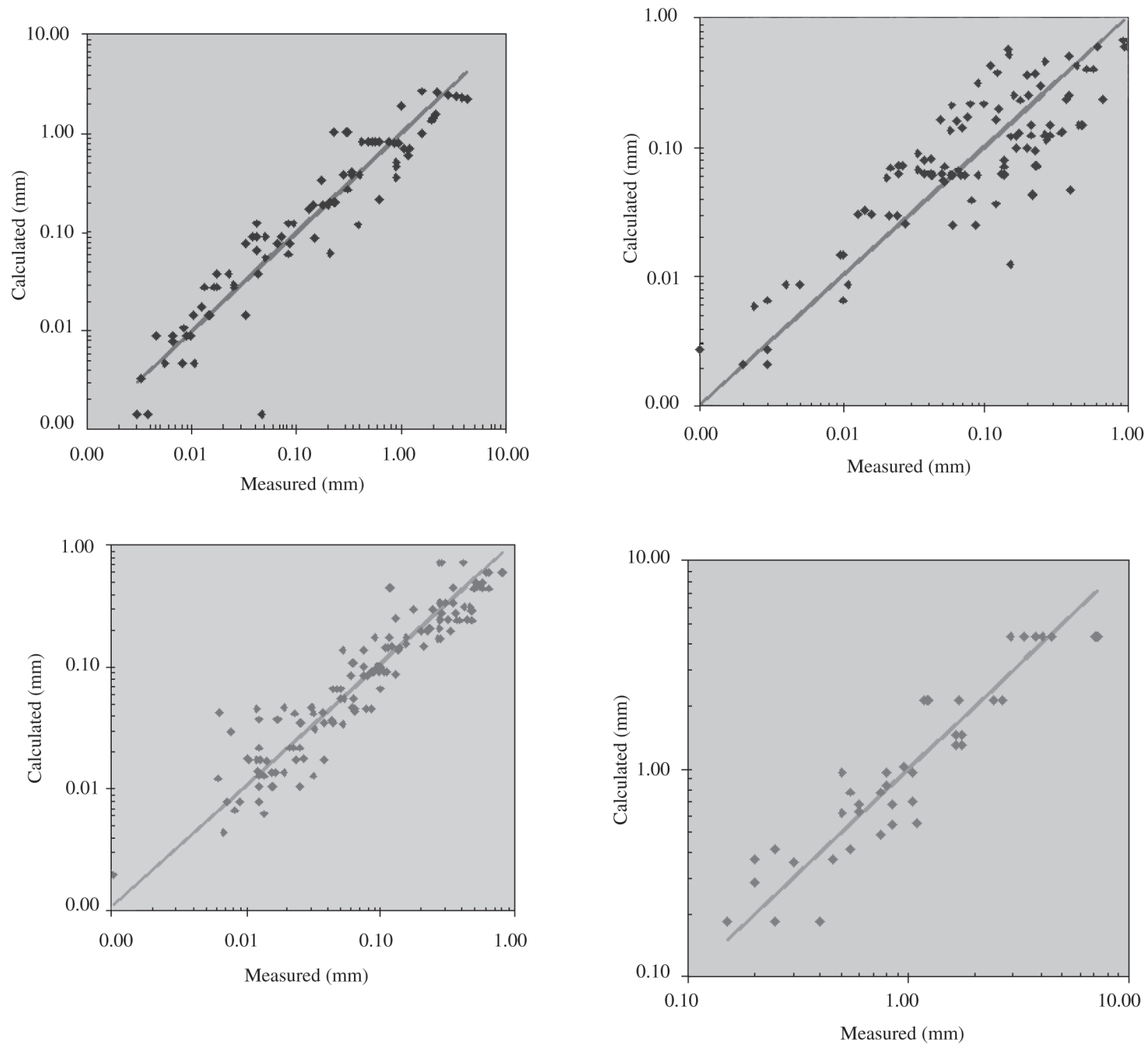

Figure 11. Examples of Correlations of Corrosion Data for Several Alloy/Corrosion Mechanisms Combinations.

discussed here may be the best available for the corrosion mechanisms an alloys that are incorporated into the system, in comparison with those made using the traditional methods of literature review and data analysis. Corrosion predicted without familiarity with the specific environment should be experimentally confirmed, if high confidence is required.

Equipment lifetime predictions as limited by corrosion depend strongly upon the corrosion rate predictions. Examples of the accuracy possible using the system are shown in Fig. 11, for several different examples of alloys and corrosion mechanisms. The correlations are quite good for three decades of variation in corrosion penetration for many alloys. The uncertainty in the predicted corrosion is typically only $\pm 50 \%$ of the predicted value.

\section{Conclusions}

This paper has reviewed a new technology delivery vehicle for high temperature corrosion science to assess metal loss information for alloys corroding in high temperature, corrosive environments. The technology has the following goals:

- Develop an objective and consistent approach to ar- 
chive and use data for alloys corroding in diverse conditions and by different mechanisms;

- Create a database to manage data on corrosion of metals and alloys corroding in complex, corrosive, and high temperature gases;

- Form a state-of-the-art capability in thermochemical calculations to determine corrosion mechanisms of alloys in industrial processes;

- Create an information system which can be applied to the following uses: equipment failure analysis, alloy evaluations to select cost effective alloys for equipment, guidelines to optimize equipment design/ operation process economics, alloy design studies, and corrosion research.

\section{Acknowledgements}

Participation and support by the following organizations are recognized and appreciated: US Department of Energy - Office of Industrial Technologies via cooperative agreement DE-FC02-00CH11020, Shell Global Solutions (US) Inc., Humberside Solutions Ltd., Centre for Research in Computational Thermochemistry in Université de Montréal, Royal Military College of Canada, Oak Ridge National Laboratory, Materials Technology Institute, Foster Wheeler Development Corporation, KEMA, Caterpillar, Special Metals Corporation, Texaco, Haynes International, Usinor Industeel, and Kvaerner Pulping Oy. Unlimited thanks are given to Owen Kriegel, who performed tests and compiled corrosion data results at Shell in Houston, Texas.

\section{References}

1. John, R.C "Oxidation Studies of Commercial Alloys at 871-1093 ${ }^{\circ} \mathrm{C}$ (1600-2000oF)" - proceed. Second International Conference on Heat Resistant Materials, Gatlinburg, TN, 11-14, Sept. 1995.

2. John, R. C. "Engineering Assessments of Oxidation of Commercial Alloys", CORROSION/96, Paper 171, National Association of Corrosion Engineers, Houston, Texas, 1996.

3. Lai, G. Y High-Temperature Corrosion of Engineering Alloys, ASM International, Materials Park, Ohio, 1990 and literature from Haynes International Marketing, "Technical Information, Oxidation Resistance of Haynes High Temperature Alloys".

4. Haycock, E.W High Temperature Metallic Corrosion of Sulfur and Its Compounds, (ed. Z. A. Foroulis), Electrochemical Society, Princeton, New Jersey, p. 110, 1970.

5. Haycock, E.W; Sharp, W.H "Corrosion of Ferrous Alloys by H2S at High Temperatures", Session from the 24th Meeting of the American Petroleum Institute, New York
1959.

6. Treseder, R. S; (ed.) Baboian, R; Munger, C. G. (co-eds.) NACE Corrosion Engineer's Reference Book, NACE International, Houston, p. 128, Texas 1991.

7. Guzeit, J "High Temperature Sulfidic Corrosion of Steels", Process Industries Corrosion - TheTheory and Practice, National association of Corrosion Engineers, Houston, Texas 1986.

8. Backensto, E. B.; Drew, R. E.; Stapleford, C. C "High Temperature Hydrogen Sulfide Corrosion", Corrosion NACE, v. 12, p. 22, 1956.

9. Sorell, G.; Hoyt, W. B "Collection and Correlation of High Temperature Hydrogen Sulfide Corrosion Data", Corrosion - NACE, v. 12, p. 213t, May 1956.

10. Lai, G. Y "Materials Behavior in High Temperature, Sulfidizing Environments", CORROSION/84, Paper 73, National Association of Corrosion Engineers, Houston, Texas, (1984). plus data from brochures Haynes 188 and Pocket Guide to Haynes Alloys from Cabot Corp 1986.

11. Stoklosa; Stringer, J "Studies of the Kinetics of Ni Sulfidation in H2S-H2 Mixtures in the Temperature Range 450-600 C", Oxidation Metals, v. 11, 263, 1977.

12. McCoy, J. D.; Hamel, F. B "Effect of Hydrodesulfurizing Process Variables on Corrosion Rates", Materials Performance, v. 10, April, p. 17, 1971.

13. John, R. C.; Fort III, W. C.; Tait, R. A "Prediction of Alloy Corrosion in the Shell Coal Gasification Process", Materials at High Temperatures, v. 11, 124, 1993.

14. Wright, I.G.; Dodds, R. O.; Palmer, R. B.; Link, H. A.; Merz, W. E.; Beatty, G. H "Correlation of the High-Temperature Corrosion Behavior of Structural Alloys in Coal Conversion Environments with the Components of the Alloys and of the Corrosive Environments", Battelle Columbus Laboratories, Columbus, Ohio, U. S. Department of Energy, Contract No. AT02-76CH92092, February $29,1980$.

15. Howes, $\mathrm{H}$ "High Temperature Corrosion in Coal Gasification Systems", final report 1 October 1972 - 31 December 1985 by IIT Research Institute, Chicago, Illinois, \#IITRI-M08251-97, for Gas Research Institute, 1987.

16. John, R.C "Alloy Corrosion in Reducing plus Sulfidizing Gases at $600-950^{\circ} \mathrm{C}$ ", High Temperature Corrosion in Energy Systems, AIME, Warrendale, PA 1985.

17. Garguet-Moulins, P.; Frampton, P. D.; Canetoli, S.; Norton, J. F "Compilation of High Temperature Corrosion Data Derived During Studies in Mixed Gaseous Atmospheres", Joint Research Centre Petten, Final Report - May 1991 (Ref. CEC/SIPM/CON/91/1).

18. Bullock, E.; Frampton, P. D.; Norton, J. F "Structural Aspects of Gaseous Carburization of Austenitic Steels", Microstructural Science, v. 9, pp. 215-224, 1981. 
19. Grabke, H. J.; Schnaas, A "Review on High-Temperature Gaseous Corrosion and Mechanical Performance in Carburizing and Oxidizing Environments", Alloy 800, pub. North Holland, pp. 195-211 1978.

20. Hurst, R. C.; Norton, J. F “The Effect of High Temperature Carburization upon the Ambient Temperature Ductility of Alloy 800H", High Temperature Technology, v. 1, no. 6, pp. 319-325, 1983.

21. Grabke, H. J "Materials Degredation by Carburization and Nitriding", 8th International Congress on Metallic Corrosion, v. 3, West Germany 6-11, September (1981, DECHEMA, pp. 2143-2156, 1981.

22. Grabke, H. J; Moller, R; Schnaas, A “Influence of Sulphur on the Carburization of a CrNiFe-alloy at High Temperatures", Werkstoffe und Korrosion, v. 30, pp. 794799, 1979.

23. Smith, G. M; Young, D. J; Trimm, D. L "Carburization Kinetics of Heat-Resistant Steels", Oxidation of Metals, v. 18, 5/6, pp. 229-243, 1982.

24. John, R. C "Alloy Carburization and Testing in Simulated Process Gases at 1800-1950O F", CORROSION/ 95, Paper 460, National Association of Corrosion Engineers, Houston, Texas 1996.

25. Thompson, W. T; Bale, C. W; Pelton, A. D "Facility for the Analysis of Chemical Thermodynamics (FACT)", McGill University Montreal, Royal Military College of Canada in Kingston, Ecole Polytechnique, Montreal, 1985.

26. John, R. C "Compilation and Use of Corrosion Data for Alloys in Various High-Temperature Gases", NACE-Cor- rosion 99, paper 73, 1999

27. John, R. C "Exploitation of Data of Alloy Corrosion in High-Temperature Gases, Materials Science Forum (Trans. Tech. Publ.), 2000, in press.

28. John, R. C "Exploitation of Data of Alloy Corrosion in High-Temperature Gases", Materials Science Forum (Trans. Tech. Publ.), 2000, in press. (presented at 5th International Symposium on High-Temperature Corrosion and Protection of Metals, May 22 - 26, 2000, Les Embiez, France.

29. John, R. C; Pelton, A. D; Young, A. L; Thompson, W. T; Wright, I. G "The ASSET Project - A Corrosion Engineering Information System for Metals in Hot Corrosive Gases", presented at the EFC - Workshop on Life Time Modeling of High Temperature Corrosion Processes, 22 and 23 February 2001, Frankfurt/Main, Germany.

30. John, R. C; Pelton, A. D.; Young, A. L.; Thompson, W. T.; Wright, I. G "ASSET, An Information System for Alloy Corrosion in High-Temperature Gases", presented at the Electrochemical Society Meeting, Electrochemical Society - High Temperature Corrosion Materials Chemistry III, March 25-30, 2001, Washington, D.C.

31. John, R. C.; Pelton, A. D.; Young, A. L.; Thompson, W. T.; Wright, I. G "Managing Corrosion Engineering Information for Metals in Hot Corrosive Gases", to be presented at the TMS and the ASM meetings in November 4-8, 2001, Indianapolis, Indiana.

32. "Database helps combat high temperature gas corrosion”, Hydrocarbon Processing, May 2001, page 93. 
